\title{
Transplastomic tobacco plants expressing a fatty acid desaturase gene exhibit altered fatty acid profiles and improved cold tolerance
}

\author{
Wendy Craig · Paolo Lenzi $\cdot$ Nunzia Scotti · Monica De Palma • \\ Paola Saggese · Virginia Carbone · Noreen McGrath Curran · Alan M. Magee • \\ Peter Medgyesy • Tony A. Kavanagh · Philip J. Dix · Stefania Grillo • \\ Teodoro Cardi
}

Received: 3 August 2007 / Accepted: 2 January 2008/Published online: 24 January 2008

(C) Springer Science+Business Media B.V. 2008

\begin{abstract}
The possibility of altering the unsaturation level of fatty acids in plant lipids by genetic transformation has implications for the stress tolerance of higher plants as well as for their nutritional value and industrial utilisation. While the integration and expression of transgenes in the plastome has several potential advantages over nuclear transformation, very few attempts have been made to manipulate fatty acid biosynthesis using plastid transformation. We produced transplastomic tobacco plants that express a $\Delta^{9}$ desaturase gene from either the wild potato species Solanum commersonii or the cyanobacterium Anacystis nidulans, using PEG-mediated DNA uptake by
\end{abstract}

Contribution no. 104 from CNR-IGV, Portici.

Wendy Craig and Paolo Lenzi contributed equally to the work.

W. Craig · P. Lenzi - N. Scotti - M. De Palma .

S. Grillo · T. Cardi $(\square)$

CNR-IGV, Institute of Plant Genetics-Portici, Portici, NA, Italy

e-mail: cardi@unina.it

P. Saggese - V. Carbone

CNR-ISA, Institute of Food Science, Avellino, AV, Italy

N. McGrath Curran · P. Medgyesy · P. J. Dix

Plant Cell Biology Laboratory, Biology Department,

NUI-Maynooth, Maynooth, Ireland

\section{A. M. Magee - T. A. Kavanagh}

Plant Molecular Biology Laboratory, Smurfit Institute of Genetics, Trinity College, Lincoln Place Gate, Dublin 2, Ireland protoplasts. Incorporation of chloroplast antibioticinsensitive point mutations in the transforming DNA was used to select transformants. The presence of the transcript and the $\Delta^{9}$ desaturase protein in transplastomic plants was confirmed by northern and western blot analyses. In comparison with control plants, transplastomic plants showed altered fatty acid profiles and an increase in their unsaturation level both in leaves and seeds. The two transgenes produced comparable results. The results obtained demonstrate the feasibility of using plastid transformation to engineer lipid metabolic pathways in both vegetative and reproductive tissues and suggest an increase of cold tolerance in transplastomic plants showing altered leaf fatty acid profiles. This is the first example of transplastomic plants expressing an agronomically relevant gene produced with the "binding-type" vectors, which do not contain a heterologous marker gene. In fact, the transplastomic plants expressing the $S$. commersonii gene contain only plant-derived sequences, a clear attraction from a public acceptability perspective.

Keywords Plastid transformation .

Stress tolerance $\cdot$ Metabolic engineering ·

Tobacco $\cdot$ Lipid metabolism

\section{Introduction}

Transplastomic plants, with the transgene inserted in the plastid genome, have been produced in tobacco 
and, more recently, in several other crop species (Daniell et al. 2005). Compared to nuclear transformation, the integration and expression of the transgene in the plastome has several potential advantages, as discussed in many original papers and literature reviews (Bock and Khan 2004; Maliga 2004; Bock 2007). However, plastid transformation has to date been applied mainly to the expression of heterologous genes involved in agronomic traits (e.g. pest or herbicide resistance) or the production of other recombinant (e.g. pharmaceutical) proteins (Bock 2007). Less focus has been made on engineering plant metabolic pathways despite the fact that many of them are completely or partially located in the various plastid types (Bock and Khan 2004; Tetlow et al. 2005; Bock 2007).

In higher plants, for example, the de novo synthesis of fatty acids is carried out in the plastids, the process initiating from the acetyl-CoA pool and proceeding by the elongation of the carbon backbone (Tetlow et al. 2005). In both the plastid and the endoplasmic reticulum, various specific desaturase enzymes control the insertion of double bonds at different positions of the fatty acid and lipid molecules (Somerville et al. 2000). Except for the $\beta$ subunit of the prokaryotictype plastidial acetyl-CoA carboxylase, whose gene is present in the plastome of most plants, all genes involved in lipid biosynthesis are located in the nucleus and the encoded enzymes, where necessary, are translocated to the plastid by a transit peptide (Madoka et al. 2002; Tetlow et al. 2005).

The unsaturation level of fatty acids (FA) in plant lipids has several implications for the stress tolerance of higher plants as well as for their nutritional value and industrial utilisation. Hence, the possibility of manipulating the lipid composition of plant cells has interesting biotechnological applications, as demonstrated by the number of transgenic plants which have been produced expressing a wide range of desaturase genes (Somerville et al. 2000).

In order to verify the possibility of manipulating the unsaturation level of fatty acids via plastid transformation, we introduced two $\Delta^{9}$ desaturase genes, derived either from the wild potato species Solanum commersonii (De Palma et al. 2008) or the cyanobacterium Anacystis nidulans (Ishizaki-Nishizawa et al. 1996), into the tobacco plastid genome. The former gene controls the conversion of ACP-stearic acid (18:0) into ACP-oleic acid $\left(18: 1^{\Delta^{9}}\right)$ in the plastid
(Somerville et al. 2000), while the latter is responsible for the production of oleic and palmitoleic $\left(16: 1^{\Delta^{9}}\right)$ acids from lipid-linked stearic and palmitic (16:0) acids, respectively, in the cyanobacterial cell (Ishizaki-Nishizawa et al. 1996). Since the unsaturation level of plant membranes can affect cold tolerance (Somerville et al. 2000), we also tested the response of transplastomic genotypes to low temperature.

Although the generation of transplastomic plants became a reality with the "binding-type" vectors based on antibiotic-insensitive mutations in plastid genes (Svab et al. 1990; Dix and Kavanagh 1995), agronomic trait manipulation by plastid transformation has been so far accomplished almost exclusively by using "dominant-type" vectors based on heterologous genes conferring antibiotic resistance (Maliga 2004; Bock 2007). Hence, to demonstrate the feasibility of using the "binding-type" vector strategy for manipulating the expression of agronomically relevant genes, the two $\Delta^{9}$ desaturase genes were cloned in vectors containing only plant-derived sequences and inserted in transgenic plastids by PEG transformation of plant protoplasts. In terms of biosafety, besides the drastic reduction in the possibility of transgene flow into the wider environment presented by transplastomic plants, the latter vectors reliance on antibiotic insensitivity means that further manipulation for the removal of marker gene(s) is obviated (Grevich and Daniell 2005; Lutz and Maliga 2007).

\section{Materials and methods}

\section{Construction of plastid expression vectors}

Two different desaturase genes (coding for a $\Delta^{9}$ stearoyl-ACP desaturase from the wild potato species S. commersonii, Scdes, GenBank accession no. $\mathrm{X} 78935$, or a $\Delta^{9}$-acyl-lipid desaturase from the cyanobacterium A. nidulans, Andes, GenBank accession no. X77367) were cloned into plastid transformation vectors, following standard cloning procedures (Sambrook et al. 1989). All cloning was confirmed by either restriction digest or direct sequencing.

Plasmid pWC1, containing expression cassette Prrn-Scdes-TpsbA, was obtained by replacing the GUS coding region in pSSH-GUS plasmid, a modified version of plastid transformation vector pSSH1 
(Kavanagh et al. 1999), with the Scdes gene region coding for the mature protein (without the putative transit peptide) as a $\mathrm{NcoI}-\mathrm{XbaI}$ fragment; whereas the pWC10 plasmid was obtained by replacing the GUS coding region in pSSH-GUS plasmid with the PCR amplified 5' blunt ended-3' XbaI Andes fragment. pWC1 and pWC10 plasmids contain the binding-type antibiotic resistance mutations from S. nigrum (Mc Cabe et al. 1989; Dix et al. 1990; Kavanagh et al. 1994), i.e. a mutation in the plastid 16S rRNA gene conferring resistance to spectinomycin and a mutation in the $3^{\prime}$ region of the plastid rpsl2 gene conferring resistance to streptomycin. They target the insertion of the transgene expression cassettes into the inverted repeat region of the tobacco plastome.

\section{Direct DNA uptake by protoplasts}

Nicotiana tabacum cv. Petit Havana shoots were used as a source of 4-6 week-old leaves for protoplast isolation for direct DNA uptake experiments. Stock plants were micropropagated in vitro by means of node culture on growth regulator-free medium containing MS salts and B5 vitamins (Duchefa, NL),

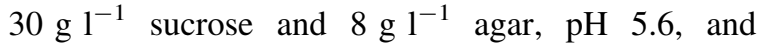
cultured at $24 \pm 2^{\circ} \mathrm{C}$ with a $16 \mathrm{~h}$ photoperiod of 50-70 $\mu \mathrm{Em}^{-2} \mathrm{~s}^{-1}$ (daylight fluorescent tubes).

For direct binding-type plasmid uptake into protoplasts, the PEG-based transformation protocol of O'Neill et al. (1993) was followed. In four experiments (two for each vector), 6.3 and $7.5 \times 10^{5}$ protoplasts were incubated with pWC1 and pWC10, respectively. Treated protoplasts were cultured in liquid K3 medium (Nagy and Maliga 1976) containing 0.4 M glucose. They were then subcultured at 5-7 days intervals, progressively reducing the osmoticum. After approximately 2 months, colonies were plated in semi-solid RMOP medium (Cséplő and Maliga 1984) containing $0.2 \mathrm{M}$ sucrose and $1 \mathrm{~g} \mathrm{l}^{-1}$ spectinomycin. Green colonies growing in this medium were transferred onto solid RMOP medium ( $2 \%$ w/v sucrose) with the same concentration of spectinomycin. Regenerated shoots were tested for double-resistance to spectinomycin and streptomycin by culturing leaf pieces on RMOP medium containing $500 \mathrm{mg} \mathrm{l}^{-1}$ of each antibiotic. Confirmed double-resistant putative transplastomic shoots were transferred to MS medium with $2 \%$ sucrose for rooting.
Polymerase chain reaction (PCR) and Southern blot analyses

Plants propagated in vitro as specified above or grown autotrophically in soil in a controlled environment room $\left(25 / 20^{\circ} \mathrm{C}, 14 / 10 \mathrm{~h}\right.$, day/night, $200 \mu \mathrm{Em}^{-2} \mathrm{~s}^{-1}$ light) were used for all molecular analyses. DNA was extracted from fresh leaf tissue $(100 \mathrm{mg})$ of putative transgenic and control plants using a DNeasy Plant Mini Kit (Qiagen) following the manufacturer's instructions. PCRs to detect the presence of desaturase genes were carried out using a primer internal to the specific desaturase gene in combination with a second one external to the flanking sequences in each vector. The following primer combinations were used for each vectorderived regenerant: LRP2 (Kavanagh et al. 1999) and wdes $3^{\prime}$ (5'-CCTCGAGTCTAGATTCAAAGTT-3'), product size $=4.0 \mathrm{~kb}(\mathrm{pWC} 1)$; LRP2 and anter $\left(5^{\prime}-\right.$ GCCACAGAACACCAGCACG- $3^{\prime}$ ), product size $=$ $3.2 \mathrm{~kb}$ (pWC10). The PCR conditions were as follows: denaturation at $94^{\circ} \mathrm{C}$ for $3 \mathrm{~min}$, then 30 cycles $\left(94^{\circ} \mathrm{C}, 1 \mathrm{~min} ; 60^{\circ} \mathrm{C}, 1 \mathrm{~min} ; 72^{\circ} \mathrm{C}, 3 \mathrm{~min}\right)$ followed by $10 \mathrm{~min}$ final extension at $72^{\circ} \mathrm{C}$.

The degree of heteroplasmy was investigated by PCR using primer pairs external to the vector flanking sequences, and by Southern analysis with a probe homologous to the plastidial sequences flanking the transgenes. For PCR analysis, the primers LRP1 and LRP2 (Kavanagh et al. 1999) were used in combination. The PCRs were carried out using AccuTaq LA DNA polymerase (Sigma) according to the manufacturer's instructions. The reaction conditions were as follows: denaturation at $94^{\circ} \mathrm{C}$ for $1 \mathrm{~min}$, then 30 cycles $\left(94^{\circ} \mathrm{C}\right.$, $30 \mathrm{~s} ; 68^{\circ} \mathrm{C}, 1 \mathrm{~min} ; 68^{\circ} \mathrm{C}, 11 \mathrm{~min}$ ) followed by $10 \mathrm{~min}$ final extension at $68^{\circ} \mathrm{C}$. Expected product sizes were $9.5 \mathrm{~kb}$ for $\mathrm{pWC1}$ vector, $9.3 \mathrm{~kb}$ for $\mathrm{pWC10}$ vector, and $7.9 \mathrm{~kb}$ for non-transformed "wild-type" tobacco, respectively. For Southern blotting, total leaf DNA $(2 \mu \mathrm{g})$ was digested with EcoRI, electrophoresed on $0.8 \%$ agarose gel and transferred to a nylon membrane (Hybond $\mathrm{N}^{+}$; Amersham) under alkaline conditions $(0.4 \mathrm{~N} \mathrm{NaOH})$. The rps12 (3')-rrn16 plastid region was amplified by PCR (Primers: 5'-GGATATCTATCTAATCCGATCG-3'， 5'-GGGCCCCCGTCAATTCC TTT- $3^{\prime}$ ), labelled by the random priming method and used as probe in Southern analysis (Scotti et al. 2003). Washed membranes were exposed to a phosphor screen 
and scanned in a Typhoon Variable Mode Imager 9200 (Amersham).

\section{RNA gel blot analyses}

Total cellular RNA was extracted from leaves of $\mathrm{T}_{0}$ transplastomic and control plants grown in soil following the guanidinium isothiocyanate method of Chomczynski and Sacchi (1987). Aliquots $(10 \mu \mathrm{g})$ of RNA were fractionated by $1.2 \%$ agarose/formaldehyde gel electrophoresis and transferred onto Hybond- $\mathrm{N}^{+}$membranes (Amersham) according to the manufacturer's instructions. The desaturase genes, Andes $(0.8 \mathrm{~kb})$ and Scdes $(1.1 \mathrm{~kb})$, were amplified by PCR and labelled by random priming using $\alpha\left[{ }^{32} \mathrm{P}\right]$-dCTP (30 Ci nmol ${ }^{-1}$ ). RNA gel blot hybridisation was carried out under high stringency conditions with $40 \%$ formamide at $42^{\circ} \mathrm{C}$. Analyses of transgene mRNA were carried out on digital scans of the relevant blots using the QuantityOne software (Biorad).

\section{SDS-PAGE and immunoblotting}

Protein extractions from Scdes transformed and control plants, grown either in vitro as shoot cultures or in soil, were carried out according to De Palma et al. (2008). Eighty microgram of total proteins were separated by SDS-PAGE on $12.5 \%$ acrylamide gel, transferred to nitrocellulose membrane and incubated with a polyclonal antibody raised against a synthetic peptide derived from the predicted S. commersonii desaturase amino acidic sequence (De Palma et al., 2008). Protein signals after Western Blotting in transplastomic plants and nuclear transgenic positive control were compared by the QuantityOne software (Biorad).

\section{Lipid and fatty acid analyses}

Lipids were extracted from fresh tissue of the second or third leaf (approx. $2 \mathrm{~cm}$ in length) from the apex of young plants (approx. $10 \mathrm{~cm}$ in height) grown in soil in a controlled environment room as previously described. Care was taken to use leaves of comparable physiological age. One gram of finely ground tissue was boiled at $100^{\circ} \mathrm{C}$ for $1-2 \mathrm{~min}$ in $4 \mathrm{ml}$ of isopropanol and then extracted for $3 \mathrm{~h}$ by shaking at room temperature with $24 \mathrm{ml}$ of a 2:1 mixture of chloroform:isopropanol. The suspension was filtered and added to $6 \mathrm{ml}$ of $0.2 \mathrm{M} \mathrm{KCl}$. After centrifugation at $3000 \mathrm{rpm}$ (Beckman GS-15R centrifuge, conical rotor GS-15R) for $5 \mathrm{~min}$, the organic phase was vacuumdried and re-suspended in $1 \mathrm{ml}$ of $0.05 \%$ BHT (Butylated hydroxytoluene, Sigma) in chloroform. Leaf lipids were trans-esterified in $2.5 \mathrm{ml}$ of sulphuric acid $0.37 \mathrm{M}$ in methanol at $80^{\circ} \mathrm{C}$ for $4 \mathrm{~h}$ using heptadecanoic acid (C17:0) as internal standard as described by Zhou et al. (1998) with the following modifications: after the reaction, two $\mathrm{ml}$ of water and $1.0 \mathrm{ml}$ of hexane were added to each tube and vortexmixed for $10 \mathrm{~min}$. The tubes were centrifuged for $1 \mathrm{~min}$ at $4000 \mathrm{rpm}$ and the hexane phase transferred to GLC vials (Alltech Associates, Inc., IL, USA). One ml of hexane was added to the aqueous phase and the extraction was carried out as described above. This step was repeated twice. For seed analyses, $25 \mathrm{mg}$ of seed samples were placed in screw cap tubes, ground with a Teflon stirring rod for $60 \mathrm{~s}$, capped and subjected to direct trans-esterification as described above.

Fatty acid methyl ester analyses were performed using a $\mathrm{GCT}^{\mathrm{TM}}$ orthogonal acceleration-Time-ofFlight (oa-TOF) GC mass spectrometer (Waters Corporation, Milford, MA, USA) equipped with a gas chromatograph GC System 6890 Series (Agilent Technologies, Palo Alto, CA, USA) fitted with a capillary column $(30 \mathrm{~m} \times 0.25 \mathrm{~mm}$ internal diameter, $0.25 \mu \mathrm{m}$ film thickness) DB-1 (J\&W Scientific, Folsom, CA, USA).

Analyses were performed with the following analytical conditions: injector temperature $280^{\circ} \mathrm{C}$, ion source temperature $200^{\circ} \mathrm{C}$ and GC-MS interface temperature $300^{\circ} \mathrm{C}$. For leaves, the initial oven temperature was $60^{\circ} \mathrm{C}$ and was programmed to increase up to $150^{\circ} \mathrm{C}$ at $15^{\circ} \mathrm{C} \mathrm{min}^{-1}$, then heated to $280^{\circ} \mathrm{C}$ at $4^{\circ} \mathrm{C} \mathrm{min}^{-1}$. Total run time was $38.5 \mathrm{~min}$. For seeds, the initial oven temperature was $40^{\circ} \mathrm{C}$ (5 min) and was programmed to increase up to $60^{\circ} \mathrm{C}$ at $4^{\circ} \mathrm{C} \mathrm{min}{ }^{-1}$, then heated to $150^{\circ} \mathrm{C}$ at $15^{\circ} \mathrm{C} \mathrm{min}{ }^{-1}$ and to $280^{\circ} \mathrm{C}$ at $3^{\circ} \mathrm{C} \mathrm{min}^{-1}$, followed by $300^{\circ} \mathrm{C}$ at $20^{\circ} \mathrm{C} \mathrm{min}^{-1}$. Total run time was $60 \mathrm{~min}$. Helium was used as carrier gas and the column flow rate was $1 \mathrm{ml} \mathrm{min}{ }^{-1}$. Mass spectrometric analyses were performed at $70 \mathrm{eV}$ ionisation energy and the 50-500 mass range was analysed with a scan time of $0.5 \mathrm{~s}$. 
Response to low temperature

To assess the stability of cellular membranes, leaf discs of $1 \mathrm{~cm}$ diameter were cut from the third fully expanded leaf of transplastomic and wild-type plants grown in soil as previously described. Discs were placed in glass tubes containing $15 \mathrm{ml}$ Milli- $\mathrm{Q}^{\mathrm{TM}}$ water (Millipore). For each genotype, three tubes (containing three discs each) per measurement were used, and the result was recorded as the mean of the replicas. Stress was imposed by placing tubes at $4^{\circ} \mathrm{C}$ for 24 or $72 \mathrm{~h}$. Ion leakage was assessed by measuring electrical conductivity $\left(\mathrm{EC}_{\text {initial }}\right)$ before (time 0 ) and after temperature stress (24 and $72 \mathrm{~h}$ ). Total electrical conductivity $\left(\mathrm{EC}_{\text {total }}\right)$ was determined after autoclaving. Total damage (Index of injury, Id) was measured using the following formula (Flint et al. 1967): $I d=100\left(R_{t}-R_{0}\right) /\left(1-R_{0}\right)$, where $\mathrm{R}_{\mathrm{t}}=\mathrm{EC}_{\text {initial }} / \mathrm{EC}_{\text {total }}$ for stressed tissues and $\mathrm{R}_{0}=\mathrm{EC}_{\text {initial }} / \mathrm{EC}_{\text {total }}$ for non-stressed tissues. Each genotype was tested 6-7 times in independent experiments.

Small seedlings, grown in Petri dishes for about 4 weeks at $24^{\circ} \mathrm{C}$ and $16 \mathrm{~h}$ light, on a medium solidified with $8 \mathrm{~g}^{-1}$ agar and containing MS salts and B5 vitamins, were transferred to a cold chamber set at $2^{\circ} \mathrm{C}$ with continuous light, about $100 \mu \mathrm{Em}^{-2} \mathrm{~s}^{-1}$. After 9 days, seedlings were classified in four classes according to the degree of damage $(0=$ green seedlings, no or very little damage; $1=$ most leaves green, some white; $2=$ most leaves white, some green; $3=$ white seedlings, very extensive damage). Similarly, 2 month-old plants in soil were tested for cold tolerance under the same conditions for 13 days. Stressed plants were scored using a scale from 0 (no or little damage) to 3 (extensive damage).

\section{Statistical analysis}

Statistical significance of differences between means for fatty acid contents in transplastomic and control genotypes was tested by analysis of variance using the Systat Package Software (Wilkinson et al. 1992). On the basis of the content of all fatty acids quantified, genotypes were grouped by the "Kmeans" clustering procedure without determining in advance the number of clusters, or by a hierarchical cluster analysis using the average linkage method and the Euclidean distance for clustering (Wilkinson et al. 1992). Data from cold tests were analyzed by analysis of variance and by $\chi^{2}$ test.

\section{Results}

Regeneration of transplastomic plants

The appearance of the first green protoplast-derived calli occurred in cultures approximately 3 months into the spectinomycin selection phase. Seven and 11 calli were obtained from $6.3 \times 10^{5}$ and $7.5 \times 10^{5}$ protoplasts treated with the pWC1 and pWC10 vectors, respectively. The calli were transferred to fresh selective medium where two thirds of them produced shoots. PCR analyses using a combination of primers internal and external to the specific expression cassette identified transplastomic plants (Fig. 1a, b). Eventually, 2 (40\%) and $5(71 \%)$ regenerated shoots proved to be transplastomic for Scdes and Andes transgenes, respectively, indicating transformation frequencies equal to $3.2-6.7$ per $10^{6}$ protoplasts treated. Homoplasmy of transplastomic plants was confirmed by PCR with primers both external to the flanking sequences on the vector (Fig. 1c), by Southern analysis (Fig. 1d) and by subsequent seed germination on selective medium (data not shown).

\section{Transgene expression}

Northern blot analysis of leaf RNA from plants transformed with the vector pWC1 using the Scdes gene as the probe detected an abundant transcript of about $1.1 \mathrm{~kb}$ and a minor transcript of approximately $2.4 \mathrm{~kb}$ (Fig. 2a). The presence of the latter transcript is consistent with readthrough transcription of adjacent genes downstream of the monocistronic Scdes expression cassette. Similar results were obtained for plants transformed with pWC10 that produced an abundant $0.8 \mathrm{~kb}$ monocistronic Andes transcript and a minor larger $2.4 \mathrm{~kb}$ readthrough RNA (Fig. 2b).

Due to the unavailability of antibodies against the cyanobacterial protein, western blot analyses could only be performed for those plants transformed with the Scdes transgene (Fig. 2c). A positive signal of about $40 \mathrm{kDa}$ was found in WC1 transplastomic 

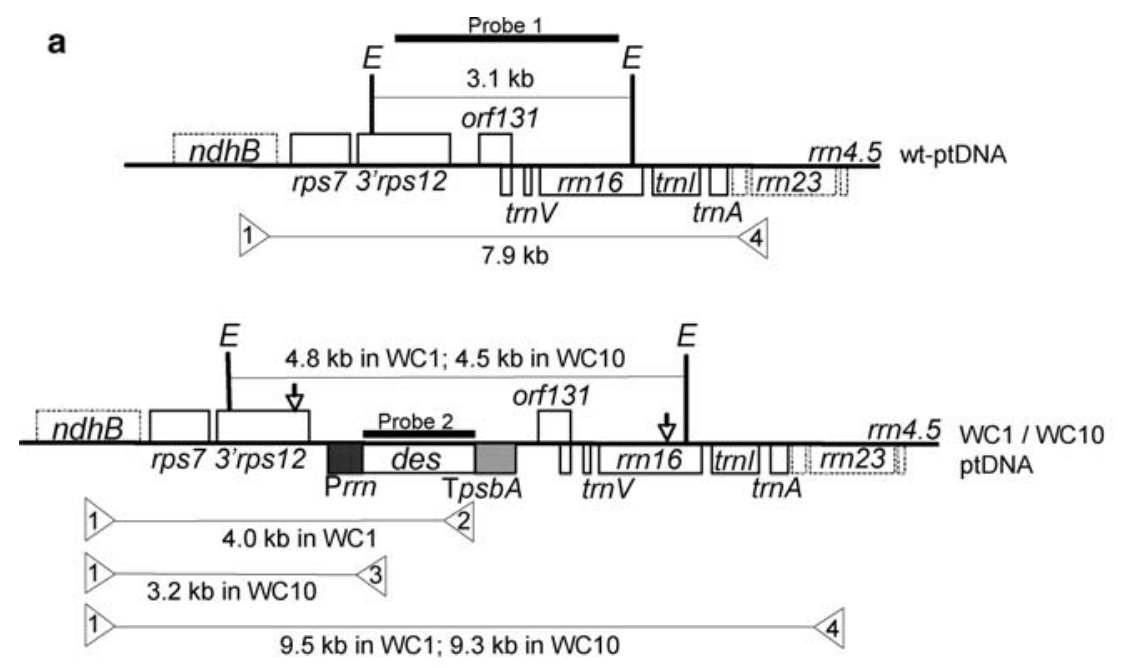
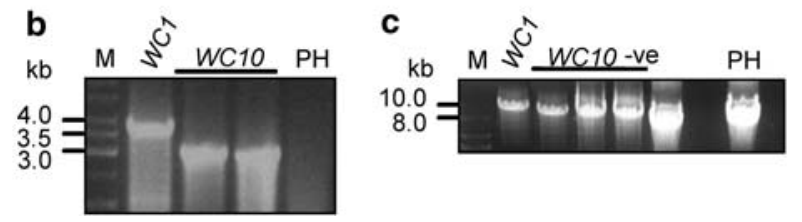

d

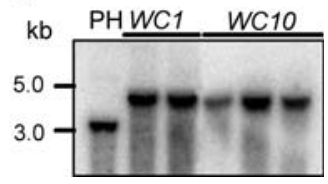

Fig. 1 Production of transplastomic plants with pWC1 and pWC10 transforming plasmids that direct insertion of the potato (Scdes) and A. nidulans (Andes) desaturase genes (des), respectively, into the inverted repeat regions of the tobacco plastome. (a) Schematic representation of the plastid genomic region involved in gene integration in transplastomic plants. Genes above and below the horizontal line are transcribed clockwise and counterclockwise, respectively, in $\mathrm{IR}_{\mathrm{B}}$ (Wakasugi et al. 1998). The approximate positions of the antibiotic resistance point mutations are indicated by short vertical arrows. Dashed boxes indicate sections not present on vector.

plants. As expected, no signal was obtained in WC10 plants with antibodies raised against the $S$. commersonii desaturase.

Leaf fatty acid analyses

Leaf fatty acid content was calculated as mole percentages for four transplastomic genotypes, with the des gene either from $S$. commersonii or $A$. nidulans, and compared to those for the two control genotypes (Petit Havana and SSHGUS-4B2) (Table 1). The latter is a transplastomic plant transformed with the original, non-modified pSSHGUS vector (McGrath Curran et al. 2003). Seven prominent fatty acids (FA) (16:0, 16:1t, 16:3, 18:0, 18:1, $18: 2$, and 18:3) were detected in leaf lipids. Although
Expected sizes of fragments derived by PCR or Southern analysis are also shown. Primers used, and their approximate localisation, are indicated by triangles: $1=\mathrm{LRP} 2$, $2=$ wdes $^{\prime}$, $3=$ anter, $4=$ LRP1 (see Materials and methods). (b) Internal/External (primers 1 and 2, or 1 and 3) and (c) External/External (primers 1 and 4) PCR analyses. (d) Southern analysis carried out with probe 1 after digestion of total cellular DNA with EcoRI. M = molecular weight marker; $-\mathrm{ve}=$ antibiotic-resistant regenerant not containing transgene insert ('mutant'); $\mathrm{PH}=$ wild-type plants; $E=E c o$ RI restriction sites

variation among genotypes was evident for some of them, differences between genotypes were generally not statistically significant when based on individual FAs. However, K-means Cluster Analysis (Wilkinson et al. 1992) carried out considering all FAs together clearly grouped the six genotypes in two main clusters, separating the four transplastomic genotypes from the two controls (Table 2). Furthermore, the latter analysis indicated that the most discriminating FAs were 16:3, 18:2, and 18:3. The transplastomic cluster had significantly $(P<0.05)$ higher levels of 16:3 and 18:3 FAs $(+23$ and $+3 \%$ increases, respectively, as percent of the control values), whilst the level of 18:2 FA was significantly lower (-28\%). Differences between clusters for the other FAs were not significant. Two main groups (transplastomic genotypes in one cluster and controls in another) were 

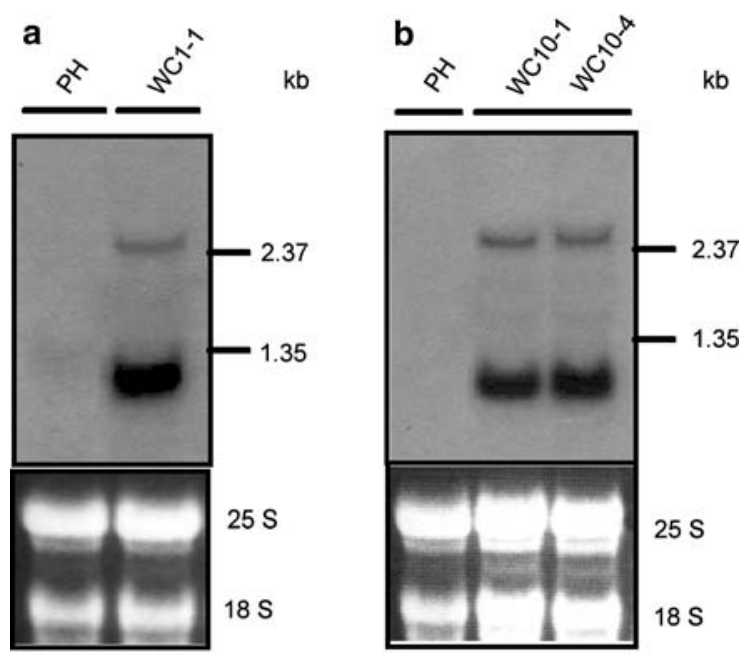

five $(16: 0,18: 0,18: 1,18: 1 t, 18: 2)$ out of the seven quantified. In comparison with Petit Havana, transplastomic genotypes had lower amounts of 16:0, 18:0, 18:1, and 18:1 $t$ FAs, along with a higher content of 18:2, the most abundant FA in tobacco seeds (Crawford and Hilditch 1950; Giannelos et al. 2002). The two transplastomic genotypes generally showed comparable levels of fatty acids. The linoleic acid content, however, was slightly, but significantly, higher in the WC1 transformants than in the WC10 lines. When FAs were considered all together, two clusters, containing transplastomic or control plants, were obtained after a K-means Cluster Analysis (Table 4). The most discriminating FAs were 18:0, 16:0, 18:2 and 18:1t, whilst differences between clusters for the other FAs were not significant. Expressing data as percent of the control values, the decrease of the two saturated FAs was -21 and $-15 \%$, respectively, whereas the increase in 18:2 content was $+4 \%$. These findings were supported by a hierarchical cluster analysis which also identified two main clusters, including transplastomic and control plants (data not shown). Within the transplastomic group, transgenic plants were again grouped according to the origin of the transgene.

Fig. 2 Expression of desaturase genes in transplastom plants. (a) Northern blot analyses performed on a WC1 transplastomic line grown in soil using Scdes gene-specific probe (probe 2, Fig. 1). (b) Northern blot analyses performed on two transplastomic WC10 lines using Andes gene-specific probe (probe 2, Fig. 1). (c) Western blot analysis with antiScDES antibodies carried out on WC1-1 plants grown either in vitro as shoot cultures (left) or in soil (right), and on a WC10 derived plant. $\mathrm{PH}=$ wild-type plant; $+\mathrm{ve}=$ potato nuclear transformant overexpressing the desaturase gene. Eighty microgram proteins were loaded for the transplastomic and the wild-type plants, and 30 for the nuclear transgenic transformant

also obtained when a hierarchical cluster analysis was carried out on the same data (data not shown). Within the transplastomic group, genotypes were grouped according to the origin of the transgene.

\section{Seed fatty acid analyses}

The seed FA content of control cv. Petit Havana and of two transplastomic genotypes containing the different des genes is reported in Table 3. Seven prominent FAs were detected in seed lipids: 16:0, 18:0, 18:1, 18:1t, 18:2, 18:2t, and 18:3. Differences between genotypes were significant $(P<0.01)$ for

\section{Response to low temperature}

To determine the effect of changes in fatty acid composition on membrane stability at chilling temperatures, control and transplastomic plants were subjected to an electrolyte leakage test. The conductivity values suggest that the membranes of transformed plants were more stable at low temperatures compared to control genotypes after 24 and $72 \mathrm{~h}$ of chilling (Fig. 3a). For both chilling treatments, the damage on the leaf discs from the plants with the cyanobacterial-derived transgene (WC10-1) was slightly lower than that on the leaf discs from the plants with the potato-derived transgene (WC1-1). However, statistical significance was detected for the stress effect $(P<0.01)$, but not for the genotype, likely due to the high error variance (i.e. variability among experiments).

Seedlings grown in Petri dishes under low temperature and continuous light also showed differential response to stress treatment (Fig. 3b). Eighty percent of Petit Havana plantlets were damaged or very 
Table 1 Mean content values of seven fatty acids in leaves of four transplastomic and two control genotypes

\begin{tabular}{lllllllll}
\hline Plant genotype $^{\mathrm{a}}$ & Transgene & \multicolumn{6}{l}{ Fatty acids (moles \%) \pm SE } \\
\cline { 3 - 9 } & & $16: 0$ & $16: 1 t$ & $16: 3$ & $18: 0$ & $18: 1$ & $18: 2$ & $18: 3$ \\
\hline PH & - & $15.17 \pm 0.25$ & $2.00 \pm 0.22$ & $3.59 \pm 0.34$ & $1.97 \pm 0.05$ & $3.63 \pm 0.56$ & $10.76 \pm 0.36$ & $62.89 \pm 1.49$ \\
SSHGUS-4B2 & - & $16.05 \pm 0.17$ & $1.91 \pm 0.17$ & $3.55 \pm 0.27$ & $1.85 \pm 0.03$ & $2.32 \pm 0.63$ & $11.74 \pm 1.12$ & $62.59 \pm 1.43$ \\
WC1-1 & Scdes & $15.90 \pm 0.51$ & $1.98 \pm 0.24$ & $4.66 \pm 0.21$ & $1.71 \pm 0.12$ & $3.12 \pm 0.80$ & $7.10 \pm 0.26$ & $65.54 \pm 0.31$ \\
WC1-2 & Scdes & $15.69 \pm 0.21$ & $2.00 \pm 0.19$ & $4.24 \pm 0.39$ & $2.13 \pm 0.41$ & $2.78 \pm 0.39$ & $8.07 \pm 0.82$ & $65.09 \pm 1.19$ \\
WC10-1 & Andes & $16.51 \pm 0.43$ & $2.05 \pm 0.07$ & $4.31 \pm 0.23$ & $1.76 \pm 0.10$ & $2.91 \pm 0.22$ & $8.90 \pm 0.38$ & $63.55 \pm 0.63$ \\
WC10-4 & Andes & $17.20 \pm 0.83$ & $2.10 \pm 0.13$ & $4.30 \pm 0.34$ & $1.68 \pm 0.17$ & $2.21 \pm 0.28$ & $8.39 \pm 1.01$ & $64.12 \pm 0.62$
\end{tabular}

${ }^{\mathrm{a}} \mathrm{PH}=$ Nicotiana tabacum, $c v$. Petit Havana; SSHGUS-4B2 = transplastomic Petit Havana with pSSHGUS vector (McGrath Curran et al. 2003); WC1 and WC10 = transplastomic plants for pWC1 and pWC10 vectors. The latter derive from pSSHGUS (see Materials and Methods). For each genotype, three independent leaf samples from plants grown in soil were analyzed b Scdes, Andes $=\Delta^{9}$ desaturase gene from Solanum commersonii or Anacystis nidulans, respectively

Table 2 Results of K-means cluster analysis with the four transplastomic (Scdes or Andes gene) and the two control genotypes. Genotypes were clustered based on the leaf content of the seven fatty acids indicated

\begin{tabular}{lccc}
\hline Fatty acid $^{\mathrm{b}}$ & F ratio $^{\mathrm{c}}$ & $\begin{array}{l}\text { Transplastomic cluster } \\
\text { Mean }^{\mathrm{a}}(\mathrm{min}-\mathrm{max})\end{array}$ & $\begin{array}{c}\text { Control cluster } \\
\text { Mean (min- max) }\end{array}$ \\
\hline $16: 3$ & $31.78^{* *}$ & $4.38(4.24-4.66)$ & $3.57(3.55-3.59)$ \\
$18: 2$ & $23.70^{* *}$ & $8.11(7.10-8.90)$ & $11.25(10.76-11.74)$ \\
$18: 3$ & $7.20^{*}$ & $64.58(63.55-65.54)$ & $62.74(62.59-62.89)$ \\
$16: 1 t$ & $2.46 \mathrm{NS}$ & $2.03(1.98-2.10)$ & $1.95(1.91-2.00)$ \\
$16: 0$ & $1.55 \mathrm{NS}$ & $16.33(15.69-17.20)$ & $15.61(15.17-16.05)$ \\
$18: 0$ & $0.31 \mathrm{NS}$ & $1.82(1.68-2.13)$ & $1.91(1.85-1.97)$ \\
$18: 1$ & $0.20 \mathrm{NS}$ & $2.75(2.21-3.12)$ & $2.98(2.32-3.63)$ \\
\hline
\end{tabular}

${ }^{a}$ K-means Cluster Analysis was carried out according to Wilkinson et al. (1992). Transplastomic cluster included WC1-1, WC1-2, WC10-1 and WC10-4 plants. Control cluster included PH and SSHGUS-4B2 plants

${ }^{\mathrm{b}}$ Listed according to decreasing $\mathrm{F}$ values from ANOVA for differences between clusters

c ** significant with $P \leq 0.01$; * significant with $P \leq 0.05$; NS: not significant $(P>0.05)$

d Moles \%

Table 3 Mean content values of seven fatty acids in seeds of two transplastomic and control genotypes

\begin{tabular}{lllllllll}
\hline Plant genotype $^{\mathrm{a}}$ & Transgene & \multicolumn{6}{l}{ Fatty acids (moles \%) \pm SE } \\
\cline { 3 - 9 } & & $16: 0$ & $18: 0$ & $18: 1$ & $18: 1 t$ & $18: 2$ & $18: 2 t$ & $18: 3$ \\
\hline PH & - & $8.26 \pm 0.13$ & $2.14 \pm 0.05$ & $11.06 \pm 0.17$ & $0.41 \pm 0.01$ & $78.04 \pm 0.31$ & $0.03 \pm 0.00$ & $0.06 \pm 0.01$ \\
WC1-1 & Scdes & $7.12 \pm 0.26$ & $1.72 \pm 0.05$ & $8.86 \pm 0.23$ & $0.24 \pm 0.03$ & $81.92 \pm 0.25$ & $0.07 \pm 0.04$ & $0.08 \pm 0.01$ \\
WC10-1 & Andes & $6.89 \pm 0.11$ & $1.67 \pm 0.02$ & $10.61 \pm 0.22$ & $0.27 \pm 0.02$ & $80.45 \pm 0.28$ & $0.03 \pm 0.00$ & $0.08 \pm 0.02$ \\
\hline
\end{tabular}

${ }^{\mathrm{a}} \mathrm{PH}=$ Nicotiana tabacum, $c v$. Petit Havana; WC1 and WC10 = transplastomic plants for pWC1 and pWC10 vectors. For each genotype, three independent seed samples were analyzed

b Scdes, Andes $=\Delta^{9}$ desaturase gene from Solanum commersonii or Anacystis nidulans, respectively

damaged (classes 2 or 3). No Petit Havana seedlings were found in the class 0 (no damage). On the other hand, $85 \%$ and $82 \%$ of WC1-1 and WC10-1 seedlings showed no or only some damage (classes 0 and 1 ).
No WC1-1 seedlings and only $4 \%$ of the WC10-1 ones were completely white (class 3 ). Similar results were obtained with plants grown in soil: $72 \%$ of transplastomic plants showed no or little damage, 
Table 4 Results of K-means cluster analysis with two transplastomic (Scdes or Andes gene) and one control genotypes. Genotypes were clustered based on the seed content of the seven fatty acids indicated

\begin{tabular}{lccc}
\hline Fatty acid $^{\mathrm{b}}$ & $\mathrm{F} \mathrm{ratio}^{\mathrm{c}}$ & $\begin{array}{l}\text { Transplastomic cluster }^{\mathrm{a}} \\
\text { Mean }^{\mathrm{d}}(\mathrm{min}-\mathrm{max})\end{array}$ & $\begin{array}{c}\text { Control cluster } \\
\text { Mean }(\mathrm{min}-\mathrm{max})\end{array}$ \\
\hline $18: 0$ & $74.41^{* *}$ & $1.69(1.64-1.83)$ & $2.14(2.05-2.21)$ \\
$16: 0$ & $32.93^{* *}$ & $7.00(6.69-7.60)$ & $8.26(8.13-8.53)$ \\
$18: 2$ & $29.72^{* *}$ & $81.18(79.92-82.34)$ & $78.04(77.43-78.43)$ \\
$18: 1 t$ & $28.21^{* *}$ & $0.25(0.17-0.31)$ & $0.41(0.39-0.42)$ \\
$18: 1$ & $4.59 \mathrm{NS}$ & $9.74(8.44-10.94)$ & $11.06(10.76-11.35)$ \\
$18: 3$ & $1.40 \mathrm{NS}$ & $0.08(0.06-0.13)$ & $0.06(0.05-0.07)$ \\
$18: 2 t$ & $0.62 \mathrm{NS}$ & $0.05(0.02-0.15)$ & $0.03(0.02-0.03)$ \\
\hline
\end{tabular}

${ }^{a}$ K-means Cluster Analysis was carried out according to Wilkinson et al. (1992). Transplastomic cluster included WC1-1 and WC10-1 plants. Control cluster included PH plants

${ }^{\mathrm{b}}$ Listed according to decreasing $\mathrm{F}$ values from ANOVA for differences between clusters

c $* *$ significant with $P \leq 0.01$; NS: not significant $(P>0.05)$

d Moles \%

whereas the majority of Petit Havana plants (89\%) showed extensive damage (Fig. 3c). In both tests, differences between genotypes were statistically significant with $P<0.001$.

\section{Discussion}

Transplastomic tobacco plants expressing either a potato or a cyanobacterial $\Delta^{9}$ fatty-acid desaturase gene were obtained in this study using a gene integration approach based on "binding-type" vectors (Dix and Kavanagh 1995) delivered by PEG transformation of leaf protoplasts. Homoplasmy, as established by molecular analyses and germination of progeny seeds on antibiotic-containing medium, was achieved directly on the primary regenerants without the need for multiple rounds of selection/regeneration, confirming results previously reported (Kavanagh et al. 1999; Nugent et al. 2005). Homoplasmic shoots were produced in about 4-5 months, which is comparable with the time required by the biolistic approach with "inactivatingtype" vectors, considering the repeated regeneration cycles on selective medium necessary to achieve homoplasmy.

Two des transcripts were observed in the leaves of both WC1 and WC10 transformants, an abundant transgenic specific monocistronic mRNA and a less abundant (20-35\% of the former) larger transcript that likely resulted from read-through transcription due to poor termination that is inherent in many plastidial $3^{\prime}$ regulatory sequences (Maliga 2002). On the other hand, a relatively weak expression of the potato desaturase protein was shown by pWC1-derived plants, being its production level about four-fold less than in the nuclear transgenic potato plant transformed with the same transgene (De Palma et al. 2008) used as positive control. In previous experiments, transplastomic plants, containing either one of the two $\Delta^{9}$ desaturase transgenes as dicistronic constructs with the selectable aadA marker gene, produced the expected transcripts at comparable levels of the plants produced in this study, but no protein could be detected (Craig et al. 2004), suggesting that limited accumulation of the $\Delta^{9}$ desaturase enzyme does not depend only on differences in mRNA abundance. The non optimal expression of the potato-derived eukaryotic transgene might depend on the prokaryotic-like features of the plastidial machinery. Unfortunately, unavailability of antibodies against the cyanobacterial enzyme prevented examination of the expression efficiency of the prokaryotic Anacystis-derived transgene. Other $5^{\prime}$ UTRs and expression cassettes could be tested to improve translation (Maliga 2002). For the purpose of metabolic engineering, however, very high levels of transgene expression may not be necessary, or even desirable (Bock 2007). Aside from some minor differences, the two transgenes generally determined comparable effects on the fatty acid composition of both leaves and seeds of transplastomic plants.

All analysed transplastomic plants showed a significant increase of trienoic fatty acids (16:3 and 18:3) 

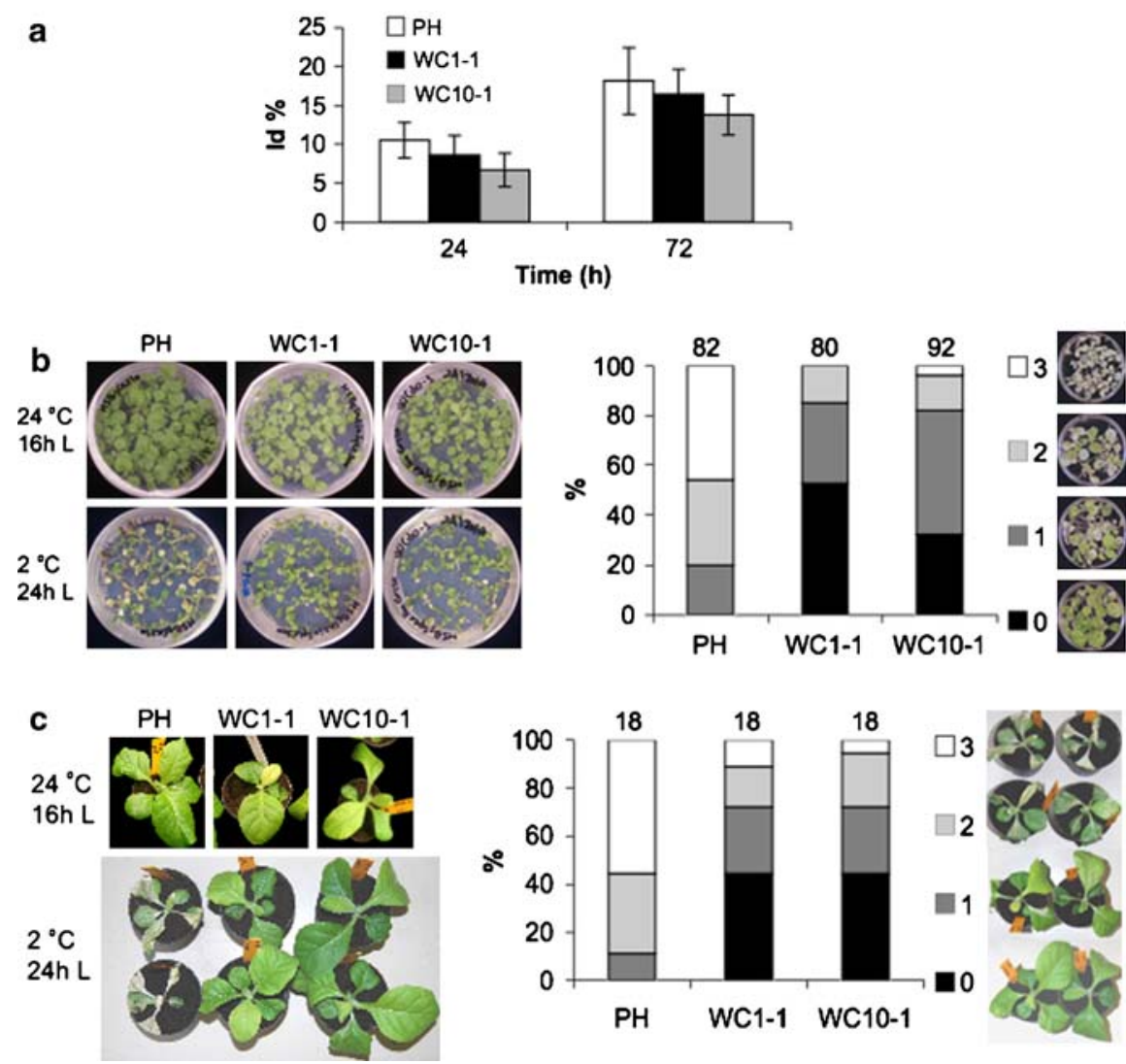

Fig. 3 Response to low temperature. (a) Results of the electrolyte leakage test carried out on leaf discs of transplastomic (WC1-1, WC10-1) and control (PH) plants grown in soil. Leaf discs were kept at $4^{\circ} \mathrm{C}$ for 24 and $72 \mathrm{~h}$ and the index of injury (Id) was measured as described in Materials and methods. Bars indicate the standard errors of the means based on 6-7 replicated experiments. b) Seedlings after exposure to $2{ }^{\circ} \mathrm{C}$ and continuous light $\left(100 \mu \mathrm{Em}^{-2} \mathrm{~s}^{-1}\right)$ for 9 days. The control and stressed seedlings grown in the Petri dishes are

and a concomitant significant reduction of dienoic linoleic acid (18:2) in leaf tissue, suggesting an overall regulation and homeostasis of the general level of unsaturation, as observed also in transgenic tobacco plants overexpressing a mammalian stearoyl-CoA $\Delta^{9}$ desaturase (Moon et al. 2000). At the same time, only minor effects were observed for the fatty acids directly involved in the reactions catalysed by the two enzymes, i.e. 16:0/16:1 and 18:0/18:1. Hence, it seems that the overexpression of the two transgenes in the plastome resulted in the accumulation of the endproducts, due to greater availability of intermediates and/or direct activation of enzymes that perform subsequent desaturation steps (Somerville et al. 2000). displayed on the left, the proportion of seedlings falling in the different classes of damage (0-3) on the right. For each genotype, the total number of seedlings analyzed is reported above each bar. (c) Representative control and stressed plants grown in soil (from left to right: $\mathrm{PH}, \mathrm{WC1} 1$, WC10-1). The proportion of plants falling in the different classes of damage (0-3) are displayed on the right side of the panel. For each genotype, the total number of plants analyzed is reported above each bar

The down-regulation of the expression of genes encoding stearoyl-ACP desaturases has been repeatedly reported and is associated with changes in fatty acid composition and alterations in various physiological traits and growth of mutants or transgenic plants (Knutzon et al. 1992; Lightner et al. 1994a, b; Merlo et al. 1998; Kachroo et al. 2001; Nandi et al. 2003). However, there are relatively few data concerning up-regulation of the same genes. The same plant-derived ACP $\Delta^{9}$ desaturase gene used in the present study has been recently overexpressed in nuclear transgenic Solanum tuberosum, exhibiting a slight increase in 18:3 and a concomitant reduction in 18:0 content. No changes were observed in 
hexadecanoic fatty acids, whereas $18: 1 \Delta^{11}$ vaccenic acid was detected in both the PC (phosphatidylcholine) and PE (phosphatidylethanolamine) microsomal fractions (De Palma et al. 2008). Similarly, Arabidopsis plants overexpressing either the SSI2 or the DES1 genes, both encoding a stearoyl-ACP $\Delta^{9}$ desaturase, were morphologically indistinguishable from wild-type plants, showing comparable 18:1 levels as well as normal salicilic acid/jasmonic acid responsiveness (Kachroo et al. 2007). The latter authors attributed the limited change in oleic acid content to tight regulation or rapid metabolization of 18:1-ACP, or to limitations of substrate or cofactor. By contrast, transgenic tobacco plants overexpressing a lupine stearoyl-ACP desaturase revealed increased unsaturated fatty acid content, in particular oleic acid (Zaborowska et al. 2002).

Unlike the soluble ACP $\Delta^{9}$ desaturase which shows only minor specificity towards free 16:0 palmitic acid (1\% of that towards 18:0 stearic acid) (McKeon and Stumpf 1982), the acyl-lipid $\Delta^{9}$ enzyme used in this study has the ability to desaturate both lipid-linked 16:0 and 18:0 fatty acids (Murata and Wada 1995; Ishizaki-Nishizawa et al. 1996). Indeed, when the corresponding gene was overexpressed in the nucleus of transgenic tobacco plants and the protein imported into the plastid, a general increase of 16:1 ( $t 3$ and $c 9$ ) and 18:1, and a concomitant reduction of 16:0, 18:0 and 18:3 fatty acids were observed in leaves. Interestingly, although the overall 16:3 fatty acid level did not change, a significant increase for this fatty acid was observed in the MGDG fraction (Ishizaki-Nishizawa et al. 1996).

Concerning the transplastomic tobacco plants produced in this study, it seems that the effect of both $\Delta^{9}$ desaturases is channeled preferentially towards the prokaryotic pathway, as suggested by the increase of hexadecatrienoic acid, a fatty acid typical of MGDG (monogalactosyldiacylglycerol) synthesised in the plastids of " $16: 3$ " plants, the latter typically synthesizing as much as $40 \%$ of leaf cell glycerolipids within the chloroplast (Somerville et al. 2000). Further, the somewhat inconsistent results reported in previous studies describing the overexpression of ACP $\Delta^{9}$ desaturase genes (Zaborowska et al. 2002; Kachroo et al. 2007; De Palma et al. 2008) suggest that differences between ours and other outcomes could be also due to the different recipient species and/or transgene used. As far as the cyanobacterial gene is concerned, in our study it was integrated and expressed within the chloroplasts, whereas in the study of Ishizaki-Nishizawa and colleagues (1996) it was integrated and transcribed in the nucleus and the resulting enzyme transferred into the chloroplast after translation in the cytoplasm. Hence, quantitative and qualitative differences between the results of the two studies could depend on differences in efficiency of transgene transcription and translation in the various cellular environments. Unfortunately, the unavailability of northern blot data in Ishizaki-Nishizawa's paper, and of western blot results in both studies, prevent the testing of this hypothesis. Furthermore, in A. nidulans cells the acyl-lipid $\Delta^{9}$ desaturase binds to the thylakoid membrane, but it remains to be established if the cyanobacterial-derived enzyme produced in the transgenic plastids retains the ability to bind to plastidial membranes.

Both 16:3 and 18:3 fatty acids are major constituents of plastidial membranes of "16:3" plants, and have important implications for plant cold tolerance (Kodama et al. 1994; Somerville et al. 2000). In particular, the unsaturation level of thylakoid membranes stabilizes the photosynthethic machinery against low-temperature photoinhibition by accelerating the recovery of the photosystem II protein complex (Moon et al. 1995). Our results suggest an increased cold tolerance in transplastomic genotypes, based on the ion leakage, and the degree of bleaching of seedlings and plants. These address only two components of cold tolerance, i.e. the stability of cellular membranes and the functionality of photosystem II (PSII), respectively. Nevertheless, they have been largely used to screen genotypes for cold tolerance (Flint et al. 1967; Ishizaki-Nishizawa et al. 1996). Indeed, the transplastomic plants containing either $\Delta^{9}$ desaturase gene showed a slight increase over the control plants as concerns membrane stability following chilling stress. Such results were confirmed when the three genotypes were kept at low temperature and continuous light, appearing both WC1-1 and WC10-1 more tolerant than Petit Havana to conditions inducing photoinhibition.

Changes in fatty composition were observed in seeds of transplastomic plants, indicating modifications also of storage lipid composition. On the whole, a significant increase in diunsaturated linoleic acid (18:2) was accompanied by a significant reduction in 
saturated 18:0 and 16:0, and, for those plants transformed with the potato-derived gene, also in 18:1 fatty acid content. This suggests activation of the extra-plastidial downstream $\Delta^{12}$ desaturase, implicated in the conversion of oleic (18:1) to linoleic acid. Since in transplastomic plants both the plant and the cyanobacterial desaturases are located in the plastid, the alteration of FA profiles in seeds implies also an increased exchange of desaturated FAs between that compartment and the cytoplasm, where further desaturation in the ER can proceed to produce increased 18:2 levels in triacylglycerols. The results obtained may have implication for the proposed industrial use of tobacco seed oil for paints or as an alternative diesel fuel (Crawford and Hilditch 1950; Giannelos et al. 2002). In addition, the increase of linoleic acid, an essential FA for mammals, in plant seeds has interesting implications in dermatology (Letawe et al. 1998; Darmstadt et al. 2002) and nutraceutics, since it can be used to produce conjugated or long-chain polyunsaturated FAs (Hornung et al. 2004; Graham et al. 2007).

Previous engineering of the lipid pathway through plastid transformation has been attempted at the level of fatty acid biosynthesis by boosting the expression of the $a c c D$ gene encoding the $\beta$ subunit of acetylCoA carboxylase (Madoka et al. 2002). Compared to control plants, transplastomic plants overexpressing the endogeneous plastidial ACCase gene showed higher fatty acid content (particularly trienoic FAs in MGDG) in leaves, extended leaf longevity, and higher seed yield. Our results demonstrate the feasibility of using plastid transformation approaches to alter fatty acid profiles in both leaves and seeds. Since plastid genome engineering provides the opportunity to stack several transgenes by coexpressing them in operons, approaches aiming to manipulate the expression of enzymes involved in different biosynthetic steps might be combined to accumulate desired fatty acids with agronomic or industrial interest.

The present study is the first to show plastid transformation with a transgene with potential agronomic interest using a "binding-type" vector, which so far has shown limited application in comparison with alternative approaches involving dominant microbial antibiotic resistance genes, such as aadA. An attraction of using antibiotic-insensitive mutations in plastid genes for selection of transformants is the ease with which homoplasmic plants are produced (Dix and Kavanagh 1995). Since only plant-derived sequences are used for gene integration and transgenic ptDNA selection, an additional advantage derives from the fact that the removal of undesired heterologous sequences (e.g. antibiotic resistance genes) is not required following the isolation of homoplasmic transformants (Grevich and Daniell 2005; Lutz and Maliga 2007). On the other hand, to achieve transformation efficiencies comparable to those attainable by biolistic delivery of "inactivatingtype" vectors, the "binding-type" approach requires an efficient protoplast-to-plant regeneration system, thus restricting the range of species to which it can be applied. The frequent homologous recombinations during plastid DNA transformation (Kavanagh et al. 1999) may also decrease the co-integration frequency of the resistance mutation and the transgene. Nevertheless, it has been used in several instances with different Nicotiana genotypes (Golds et al. 1993; O’Neill et al. 1993; Kavanagh et al. 1999; Horváth et al. 2000; Rumeau et al. 2004; Buhot et al. 2006) and also with tomato (Nugent et al. 2005), exploiting either homologous or homeologous recombination for transgene integration.

Acknowledgements The work was partially funded by the European Union 5th Framework Programme, project "The Plastid Factory" (QLK3-CT-1999-00692). We thank Dr. T. Toguri, Kirin Brewery Co., Yokohama, Japan for generously providing the desaturase cDNA from A. nidulans, and Ms. A. Morgese, Mr. P. Palmieri, Mr. A. Piccolo and Ms. L. Sannino for their excellent technical assistance.

\section{References}

Bock R (2007) Plastid biotechnology: prospects for herbicide and insect resistance, metabolic engineering and molecular farming. Curr Opin Biotechnol 18:100-106

Bock R, Khan MS (2004) Taming plastids for a green future. Trends Biotechnol 22:311-318

Buhot L, Horvàth E, Medgyesy P, Lerbs-Mache S (2006) Hybrid transcription system for controlled plastid transgene expression. Plant J 46:700-707

Chomczynski P, Sacchi N (1987) Single-step method of RNA isolation by acid guanidinium thiocyanate-phenolchloroform extraction. Anal Biochem 162:156-159

Craig W, Lenzi P, De Palma M, Saggese P, Dix PJ, Curran NM, Medgyesy P, Carbone V, Scotti N, Grillo S and Cardi T (2004) Plastid transformation for the production of unsaturated fatty acids: molecular and biochemical characterization of tobacco transplastomic plants expressing $\Delta 9$ desaturase genes. Proceedings of the 
XLVIII Italian Society of Agricultural Genetics-SIFVSIGA Joint Meeting Lecce, Italy, September 15-18, 2004

Crawford RV, Hilditch TP (1950) The component fatty acids of tobacco-seed oils. J Sci Food Agric 1:230-234

Cséplő A, Maliga P (1984) large scale isolation of maternally inherited lincomycinresistance mutations, in diploid Nicotiana plumbaginifolia protoplast cultures. Mol Gen Genet 196:407-412

Daniell H, Kumar S, Dufourmantel N (2005) Breakthrough in chloroplast genetic engineering of agronomically important crops. Trends Biotechnol 23:238-245

Darmstadt GL, Mao-Qiang M, Chi E, Saha SK, Ziboh VA, Black RE, Santosham M, Elias PM (2002) Impact of topical oils on the skin barrier: possible implications for neonatal health in developing countries. Acta Paediatr 91:546-554

De Palma M, Grillo S, Massarelli I, Costa A, Balogh G, Vigh L, Leone A (2008) Regulation of desaturase gene expression, changes in membrane lipid composition and freezing tolerance in potato plants. Mol Breed 21:15-26

Dix PJ, Kavanagh TA (1995) Transforming the plastome: genetic markers and DNA delivery systems. Euphytica 85:29-34

Dix PJ, McKinley CP, Mc Cabe PF (1990) Antibiotic resistant mutants of Solanum nigrum. In: Nijkamp HJJ, Van Der Plas LHW, Van Aartijk J (eds) Progress in plant cellular and molecular biology. Kluwer Academic Publishers, Dordrecht, Boston, London, pp 169-174

Flint HL, Boyce BK, Beattie DJ (1967) Index of injury-a useful expression of freezing injury to plant tissues as determined by the electrolytic method. Can J Plant Sci 47:229-230

Giannelos PN, Zannikos F, Stournas S, Lois E, Anastopoulos G (2002) Tobacco seed oil as an alternative diesel fuel: physical and chemical properties. Ind Crop Prod 16:1-9

Golds T, Maliga P, Koop HU (1993) Stable plastid transformation in PEG-treated protoplasts of Nicotiana tabacum. Biotechnology 11:95-97

Graham IA, Larson T, Napier JA (2007) Rational metabolic engineering of transgenic plants for biosynthesis of omega-3 polyunsaturates. Curr Opin Biotechnol 18:1-6

Grevich JJ, Daniell H (2005) Chloroplast genetic engineering: recent advances and future perspective. Crit Rev Plant Sci 24:83-107

Hornung E, Saalbach I and Feussner I (2004) Production of conjugated fatty acids in plants. Proceedings of the 16th International Plant Lipid Symposium. Budapest, Hungary, June 1-4, 2004

Horváth EM, Peter SO, Joët T, Rumeau D, Cournac L, Horváth GV, Kavanagh TA, Schäfer C, Peltier G, Medgyesy P (2000) Targeted inactivation of the plastid $n d h B$ gene in tobacco results in enhanced sensitivity of photosynthesis to moderate stomatal closure. Plant Physiol 123:1337-1349

Ishizaki-Nishizawa O, Fujii T, Azuma M, Sekiguchi K, Murata N, Ohtani T, Toguri T (1996) Low-temperature resistance of higher plants is significantly enhanced by a nonspecific cyanobacterial desaturase. Nat Biotechnol 14:1003-1006

Kachroo P, Shanklin J, Shah J, Whittle EJ, Klessig DF (2001) A fatty acid desaturase modulates the activation of defense signaling pathways in plants. Proc Natl Acad Sci USA 98:9448-9453
Kachroo A, Shanklin J, Whittle E, Lapchyk L, Hildebrand D, Kachroo P (2007) The Arabidopsis stearoyl-acyl carrier protein-desaturase family and the contribution of leaf isoforms to oleic acid synthesis. Plant Mol Biol 63: 257-271

Kavanagh TA, O’Driscoll KM, McCabe PF, Dix PJ (1994) Mutations conferring lincomycin, spectinomycin, and streptomicyn resistance in Solanum nigrum are located in three different chloroplast genes. Mol Gen Genet 242:675-680

Kavanagh TA, Thanh ND, Lao NT, McGrath N, Peter SO, Horvath EM, Dix PJ, Medgyesy P (1999) Homeologous plastid DNA transformation in tobacco is mediated by multiple recombination events. Genetics 152:1111-1122

Knutzon DS, Thompson GA, Radke SE, Johnson WB, Knauf VC, Kridle JC (1992) Modification of Brassica seed oil by antisense expression of a stearoyl-acyl carrier protein desaturase gene. Proc Natl Acad Sci USA 89:2624-2628

Kodama H, Hamada T, Horiguchi G, Nishimura M, Iba K (1994) Genetic enhancement of cold tolerance by expression of a gene for chloroplast $\omega-3$ fatty acid desaturase in transgenic tobacco. Plant Physiol 105: $601-605$

Letawe C, Boone M, Piérard GE (1998) Digital image analysis of the effect of topically applied linoleic acid on acne microcomedones. Clin Exp Dermatol 23:56-58

Lightner J, Wu J, Browse J (1994a) A mutant of Arabidopsis with increased levels of stearic acid. Plant Physiol 106:1443-1451

Lightner J, James DW, Dooner HK, Browse J (1994b) Altered body morphology is caused by increased stearate levels in a mutant of Arabidopsis. Plant J 6:401-412

Lutz KA, Maliga P (2007) Construction of marker-free transplastomic plants. Curr Opin Biotechnol 18:107-114

Madoka Y, Tomizawa K-I, Mizoi J, Nishida I, Nagano Y, Sasaki Y (2002) Chloroplast transformation with modified accD operon increases acetyl-CoA carboxylase and causes extension of leaf longevity and increase in seed yield in tobacco. Plant Cell Physiol 43:1518-1525

Maliga P (2002) Engineering the plastid genome of higher plants. Curr Opin Plant Biol 5:164-172

Maliga P (2004) Plastid transformation in higher plants. Annu Rev Plant Biol 55:289-313

Mc Cabe PF, Timmons PJ, Dix PJ (1989) A simple procedure for the isolation of streptomycin resistant plants in Solanaceae. Mol Gen Genet 216:132-137

McGrath Curran N, Shiel K, Nugent J, Kavanagh T and Dix P (2003) Chloroplast transformation of tobacco using nonbacterial selectable marker genes. Proceedings of the 7th International Congress of Plant Molecular Biology, Barcelona, Spain, June 23-28, 2003

McKeon TA, Stumpf PK (1982) Purification and characterization of the stearoyl-acyl carrier protein desaturase and the acyl-acyl carrier protein thioesterase from maturing seeds of safflower. J Biol Chem 257:12141-12147

Merlo AO, Cowen N, Delate T, Edington B, Folkerts O, Hopkins N, Lemeiux C, Skokut T, Smith K, Woosley A, Yang Y, Young S, Zwick M (1998) Ribozymes targeted to stearoyl-ACP $\Delta 9$ desaturase mRNA produce heritable increases of stearic acid in transgenic maize leaves. Plant Cell 10:1603-1622 
Moon BY, Higashi SI, Gombos Z, Murata N (1995) Unsaturation of the membrane lipids of chloroplasts stabilizes the photosynthetic machinery against low-temperature photoinhibition in transgenic tobacco plants. Proc Natl Acad Sci USA 92:6219-6223

Moon H, Hazebroek J, Hildebrand DF (2000) Changes in fatty acid composition in plant tissues expressing a mammalian $\Delta 9$ desaturase. Lipids 35:471-479

Murata N, Wada H (1995) Acyl-lipid desaturases and thier importance in the tolerance and acclimatization to cold of cyanobacteria. Biochem J 308:1-8

Nagy JI, Maliga P (1976) Callus induction and plant regeneration from mesophyll protoplasts of Nicotiana sylvestris. Z Pflanzephysiol 78:453-455

Nandi A, Krothapalli K, Buseman CM, Li M, Welti R, Enyedi A, Shah J (2003) Arabidopsis sfd mutants affect plastidic lipid composition and suppress dwarfing, cell death, and the enhanced disease resistance phenotypes resulting from the deficiency of a fatty acid desaturase. Plant Cell $15: 2383-2398$

Nugent GD, ten Have M, van der Gulik A, Dix PJ, Uijtewaal BA, Mordhorst AP (2005) Plastid transformants of tomato selected using mutations affecting ribosome structure. Plant Cell Rep 24:341-349

O'Neill C, Horvath GV, Horvath E, Dix PJ, Medgyesy P (1993) Chloroplast transformation in plants: polyethylene glycol (PEG) treatment of protoplasts is an alternative to biolistic delivery systems. Plant J 3:729-738

Rumeau D, Bécuwe-Linka N, Beyly A, P. C, Cuiné S, Genty B, Medgyesy P, Horvath E, Peltier G (2004) Increased zinc content in transplastomic tobacco plants expressing a polyhistidine-tagged Rubisco large subunit. Plant Biotechnol J 2:389-399
Sambrook J, Fritsch EF, Maniatis T (1989) Molecular cloning, a laboratory manual, 2nd ed. Cold Spring Harbor Laboratory Press, Cold Spring Harbor, NY

Scotti N, Monti L, Cardi T (2003) Organelle DNA variation in parental Solanum spp. genotypes and nuclear-cytoplasmic interactions in Solanum tuberosum (+) S. commersonii somatic hybrid-backcross progeny. Theor Appl Genet 108:87-94

Somerville C, Browse J, Jaworski JG, Ohlrogge JB (2000) Lipids. In: Buchanan BGW, Jones R (eds) Biochemistry \& molecular biology of plants. American Society of Plant Physiologists, Rockville, USA

Svab Z, Hajdukiewicz P, Maliga P (1990) Stable transformation of plastids in higher plants. Proc Natl Acad Sci USA 87:8526-8530

Tetlow IJ, Rawsthorne S, Raines C, Emes MJ (2005) Plastid metabolic pathways. In: Moller SG (ed) Plastids. Blackwell Publishing, Oxford, pp 60-125

Wakasugi T, Sugita M, Tsudzuki T, Sugiura M (1998) Update gene map of tobacco chloroplast DNA. Plant Mol Biol Rep 16:231-241

Wilkinson L, Hill MA, Vang E (1992) SYSTAT: statistics. Version 5.2 edn. SYSTAT Inc., Evanston

Zaborowska Z, Starzycki M, Femiak I, Swiderski M, Legocki AB (2002) Yellow lupine gene encoding stearoyl-ACP desaturase-organization, expression and potential application. Acta Biochim Pol 49:29-42

Zhou MX, Glennie Holmes M, Robards K, Helliwell S (1998) Fatty acid composition of lipids of australian oats. J Cereal Sci 28:311-319 